\title{
Ticagrelor versus Clopidogrel in Symptomatic Peripheral Artery Disease
}

\author{
William R. Hiatt, M.D., F. Gerry R. Fowkes, M.D., Gretchen Heizer, M.S., \\ Jeffrey S. Berger, M.D., Iris Baumgartner, M.D., Peter Held, M.D., Ph.D., \\ Brian G. Katona, Pharm.D., Kenneth W. Mahaffey, M.D., \\ Lars Norgren, M.D., Ph.D., W. Schuyler Jones, M.D., Juuso Blomster, M.D., \\ Marcus Millegård, M.Sc., Craig Reist, Ph.D., and Manesh R. Patel, M.D., \\ for the EUCLID Trial Steering Committee and Investigators*
}

ABSTRACT

From the University of Colorado School of Medicine and CPC Clinical Research, Aurora (W.R.H.); Usher Institute of Population Health Sciences and Informatics, University of Edinburgh, Edinburgh (F.G.R.F.); Duke Clinical Research Institute, Duke University School of Medicine, Durham, NC (G.H., W.S.J., C.R., M.R.P.); the Departments of Medicine and Surgery, New York University School of Medicine, New York (J.S.B.); Swiss Cardiovascular Center, Inselspital, Bern University Hospital, University of Bern, Bern, Switzerland (I.B.); AstraZeneca Gothenburg, Mölndal (P.H., J.B., M.M.), and Faculty of Medicine and Health, Örebro University, Örebro (L.N.) - both in Sweden; AstraZeneca Gaithersburg, Gaithersburg, MD (B.G.K.); and Stanford Center for Clinical Research, Stanford University School of Medicine, Stanford, CA (K.W.M.). Address reprint requests to $\mathrm{Dr}$. Patel at Duke Clinical Research Institute, Duke University Medical Center, 2400 Pratt St., Rm. 0311 Terrace Level, Durham, NC 27705, or at manesh.patel@duke.edu.

*A complete list of steering committee members and investigators in the Examining Use of Ticagrelor in Peripheral Artery Disease (EUCLID) trial is provided in the Supplementary Appendix, available at NEJM.org.

This article was published on November 13, 2016, at NEJM.org.

N EnglJ Med 2017;376:32-40. DOI: 10.1056/NEJMoal611688

Copyright (๑) 2016 Massachusetts Medical Society.

\section{BACKGROUND}

Peripheral artery disease is considered to be a manifestation of systemic atherosclerosis with associated adverse cardiovascular and limb events. Data from previous trials have suggested that patients receiving clopidogrel monotherapy had a lower risk of cardiovascular events than those receiving aspirin. We wanted to compare clopidogrel with ticagrelor, a potent antiplatelet agent, in patients with peripheral artery disease.

\section{METHODS}

In this double-blind, event-driven trial, we randomly assigned 13,885 patients with symptomatic peripheral artery disease to receive monotherapy with ticagrelor $(90 \mathrm{mg}$ twice daily) or clopidogrel ( $75 \mathrm{mg}$ once daily). Patients were eligible if they had an ankle-brachial index (ABI) of 0.80 or less or had undergone previous revascularization of the lower limbs. The primary efficacy end point was a composite of adjudicated cardiovascular death, myocardial infarction, or ischemic stroke. The primary safety end point was major bleeding. The median follow-up was 30 months.

\section{RESULTS}

The median age of the patients was 66 years, and $72 \%$ were men; $43 \%$ were enrolled on the basis of the $\mathrm{ABI}$ and $57 \%$ on the basis of previous revascularization. The mean baseline ABI in all patients was $0.71,76.6 \%$ of the patients had claudication, and $4.6 \%$ had critical limb ischemia. The primary efficacy end point occurred in 751 of 6930 patients (10.8\%) receiving ticagrelor and in 740 of 6955 (10.6\%) receiving clopidogrel (hazard ratio, 1.02; 95\% confidence interval [CI], 0.92 to 1.13; $\mathrm{P}=0.65$ ). In each group, acute limb ischemia occurred in $1.7 \%$ of the patients (hazard ratio, 1.03; 95\% CI, 0.79 to $1.33 ; \mathrm{P}=0.85$ ) and major bleeding in $1.6 \%$ (hazard ratio, $1.10 ; 95 \% \mathrm{CI}, 0.84$ to $1.43 ; \mathrm{P}=0.49$ ).

\section{CONCLUSIONS}

In patients with symptomatic peripheral artery disease, ticagrelor was not shown to be superior to clopidogrel for the reduction of cardiovascular events. Major bleeding occurred at similar rates among the patients in the two trial groups. (Funded by AstraZeneca; EUCLID ClinicalTrials.gov number, NCT01732822.) 
P ERIPHERAL ARTERY DISEASE IS CONSIDered to be a clinical manifestation of systemic atherosclerosis affecting the vascular territories supplying the lower limbs. Most patients presenting with peripheral artery disease do not have a clinical history of cardiac or cerebral ischemic events, yet these patients are at high risk for myocardial infarction, ischemic stroke, and cardiovascular death. ${ }^{1}$ Concomitant clinical evidence of coronary or cerebrovascular disease only magnifies this risk. ${ }^{2}$

Therapies to reduce the ischemic risk associated with atherosclerosis have focused on patients with acute coronary syndromes and stable coronary artery disease. Antithrombotic drugs, mainly antiplatelet therapies and statins, are the cornerstone of care. There have been no large trials focusing on patients with peripheral artery disease, which has led to limited direct evidence to support any guideline recommendations for specific antiplatelet therapies in such patients. ${ }^{3,4}$ Clopidogrel monotherapy has been shown to be more effective than aspirin monotherapy in reducing cardiovascular events in a subgroup of patients with peripheral artery disease in a comparison with patients with other forms of stable cardiovascular disease. ${ }^{3}$

Ticagrelor, an inhibitor of platelet $\mathrm{P}_{2} \mathrm{Y}_{12}$ receptor, has shown evidence of benefit among patients with acute coronary syndromes and stable coronary artery disease, as defined by a history of myocardial infarction.5,6 Concomitant peripheral artery disease in patients with an acute coronary syndrome event increases the risk of subsequent cardiovascular events. In a recent trial involving patients with acute coronary syndromes, ticagrelor resulted in a relative risk reduction similar to the reduction in the overall trial, but the drug was associated with a larger absolute risk reduction in a comparison with patients who had an acute coronary syndrome without peripheral artery disease. ${ }^{7}$ In another clinical trial, patients with a history of myocardial infarction and concomitant peripheral artery disease also had a greater risk of cardiovascular events and a greater absolute risk reduction with ticagrelor than did patients with previous myocardial infarction alone. ${ }^{8}$ On the basis of previous observations and the need to develop evidence for specific therapies, we performed the Examining Use of Ticagrelor in Peripheral Artery Disease (EUCLID) trial to test the hypothesis that monotherapy with ticagrelor would be superior to therapy with clopidogrel in preventing cardiovascular death, myocardial infarction, or ischemic stroke in patients with symptomatic peripheral artery disease.

\section{METHODS}

\section{TRIAL DESIGN}

The details regarding the study design for our trial have been published previously. ${ }^{9}$ Briefly, this was a double-blind, active-comparator clinical trial involving 13,885 patients with symptomatic peripheral artery disease at 811 sites in 28 countries. (Details are provided in the Supplementary Appendix, available with the full text of this article at NEJM.org.) The trial was designed by an independent executive committee that included members from the Duke Clinical Research Institute, the Colorado Prevention Center at the University of Colorado, and AstraZeneca, the trial sponsor. An international steering committee was responsible for oversight of local study sites and included national lead investigators from each country. All primary efficacy and safety end points were adjudicated by an independent clinical events committee in a blinded fashion. An independent data and safety monitoring committee provided safety oversight and performed one formal interim analysis after 798 primary events had been adjudicated.

The Duke Clinical Research Institute held the clinical database and conducted all analyses for publication independent of the sponsor. The first draft of the manuscript was written by the first and last authors, and all the coauthors participated in the oversight of the trial and in the preparation of all subsequent drafts of the manuscript. The executive committee and authors assume responsibility for the accuracy and completeness of the data and all analyses, as well as the fidelity of this trial to the protocol and statistical analysis plan (available at NEJM.org). AstraZeneca provided financial support for the conduct of the study.

\section{STUDY POPULATION}

Eligible patients were at least 50 years of age with symptomatic peripheral artery disease. Patients were required to have one of two inclusion criteria: previous revascularization of the lower limbs for symptomatic disease more than 30 days before randomization or hemodynamic evidence of peripheral artery disease, as evidenced by an 
ankle-brachial index (ABI) of 0.80 or less at screening. (The ABI is the ratio of the systolic blood pressure in the ankle to the blood pressure in the upper arm, with lower values indicating possible narrowing of the arteries in the legs.) For patients qualifying for enrollment on the basis of the $\mathrm{ABI}$ criterion, the measure was repeated at the randomization visit and required a value 0.85 or less to ensure that patients had reproducible evidence of substantial atherosclerotic disease burden. In patients with an ABI of 1.40 or more (an indication of calcification of the tibial arterial wall and stiffening of the vessel), the ankle systolic pressures are falsely elevated. In that situation, the toe-brachial index (TBI), the ratio of the systolic blood pressure in the large toe to the blood pressure in the upper arm, was used if the value was 0.60 or less at screening and 0.65 or less at randomization. Key exclusion criteria included current or planned use of dual antiplatelet therapy or aspirin, an increased risk of bleeding, treatment with long-term anticoagulation, or a poor clopidogrel metabolizer status for the cytochrome P-450 2C19 allele, defined as a genotype with two loss-of-function alleles. All the patients provided written informed consent for participation.

\section{RANDOMIZATION AND STUDY TREATMENT}

Patients underwent randomization in a 1:1 ratio in a double-blind fashion to receive either ticagrelor (90 mg twice daily) or clopidogrel (75 mg once daily). Randomization was performed with the use of an interactive voice-response or Web-response system.

\section{END POINTS}

The primary efficacy end point was the first occurrence of any event in the composite of cardiovascular death, myocardial infarction, or ischemic stroke (defined as any stroke not shown to be primarily hemorrhagic). Secondary end points were tested in a hierarchical fashion beginning with the primary end point plus acute limb ischemia leading to hospitalization. The primary safety end point was major bleeding, according to Thrombolysis in Myocardial Infarction (TIMI) criteria.

\section{STATISTICAL ANALYSIS}

We determined that a sample size of 11,500 patients and 1596 primary end points would provide a power of $90 \%$ to determine the superiority of ticagrelor over clopidogrel, assuming that the primary end point would occur in $7 \%$ of the patients in the clopidogrel group annually and that the patients in the ticagrelor group would have a $15 \%$ lower relative risk than those in the clopidogrel group (i.e., hazard ratio, 0.85) at a $4.94 \%$ significance level that was adjusted for one interim analysis. ${ }^{9}$ However, given a lower-thanexpected primary-event rate, the sample size was increased to approximately 13,500 patients and the power was decreased to $85 \%$, which required a minimum of 1364 primary end-point events.

The primary and secondary efficacy analyses were performed according to the intention-totreat principle and included all the patients who had undergone randomization, regardless of adherence to the protocol or study-drug assignment and of continued participation in the study. Patients who withdrew consent to participate in the study were included up to the date of withdrawal, with the exception of the analysis of death from any cause, in which we included information from all the patients for whom vital status could be determined from public records at the end of the study. The safety analyses included all the patients who received at least one dose of a trial drug during the treatment period, which was defined as up to 7 days after the last dose of a trial drug.

We used a Cox proportional-hazards model to analyze the primary and secondary time-to-event analyses with a factor for the treatment group. $\mathrm{P}$ values and confidence intervals for the hazard ratios were based on the Wald statistic. We calculated Kaplan-Meier estimates of the cumulative proportion of patients with events, with the number of patients at risk indicated below the plot at specific time points. No multiplicity adjustment was made to confidence intervals, and all $\mathrm{P}$ values were unadjusted.

In efficacy time-to-event analyses, we censored data for patients in whom the event in question had not occurred at either the censoring date for the primary analysis or the last trial contact when all components of the end point in question were assessed, whichever came first.

\section{RESULTS}

\section{PATIENTS}

From December 2012 through March 2014, a total of 16,237 patients were enrolled and screened for randomization. A total of 13,885 patients underwent randomization and were followed for the occurrence of the composite primary events 


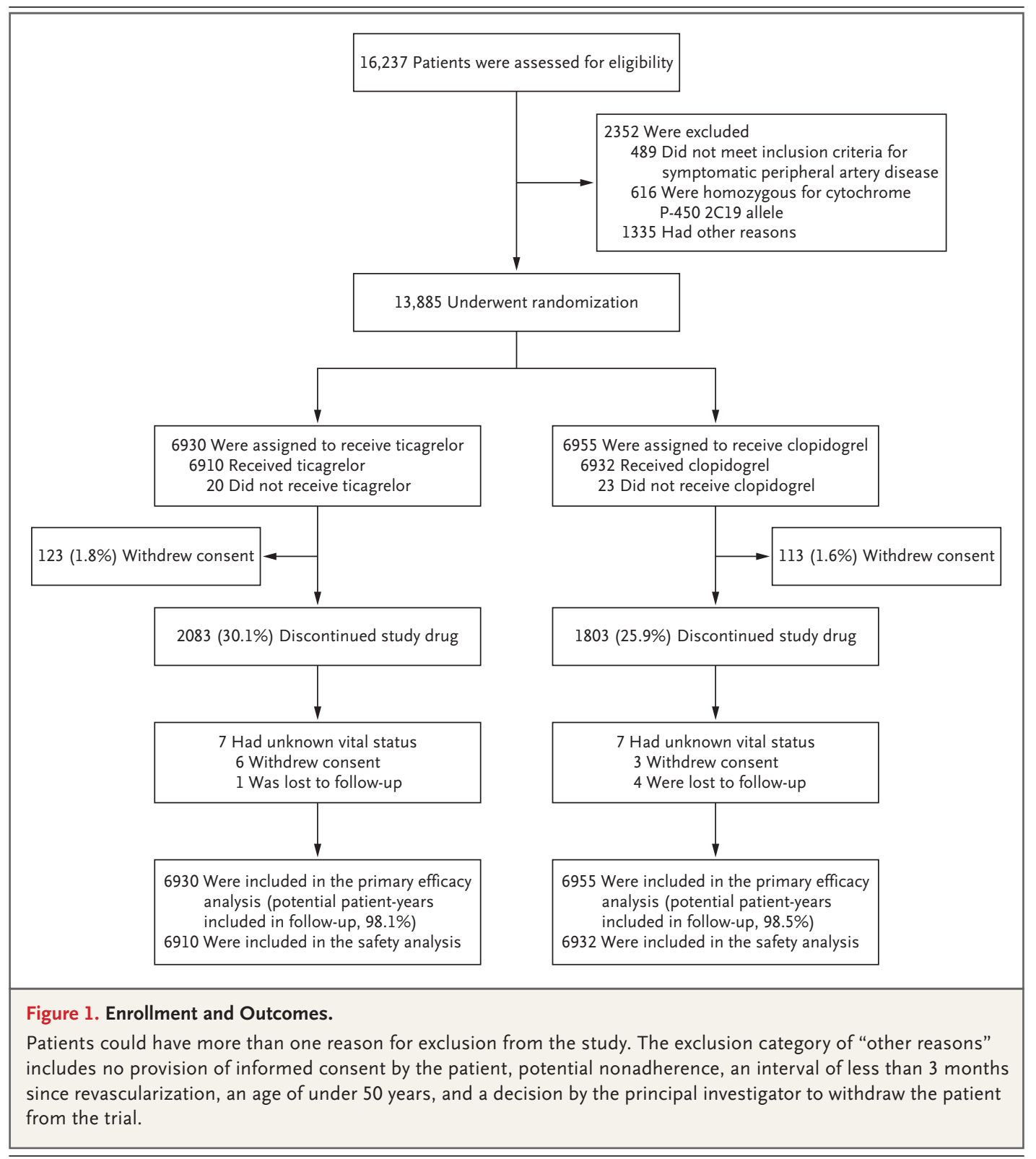

through May 9, 2016. At the completion of the trial, vital status was unknown for 14 patients; of these patients, 5 were lost to follow-up (Fig. 1). The median follow-up was approximately 30 months.

The characteristics of the patients were well balanced in the two groups (Table 1). The median age of the patients was 66 years, and $72 \%$ were male. Enrollment was based on an abnormal ABI or TBI in 6010 patients $(43 \%)$ and on previous revascularization in 7875 (57\%). The mean baseline $\mathrm{ABI}$ in all the patients was 0.71 , and the $\mathrm{ABI}$ according to recruitment stratum is presented in Table 1 . The majority of patients had claudication $(76.6 \%), 4.6 \%$ had critical limb ischemia, and $18.7 \%$ were asymptomatic. (Among the asymptomatic patients, $95 \%$ had undergone previous revascularization for symptomatic disease.)

\section{EFFICACY END POINTS}

The primary efficacy composite end point of cardiovascular death, myocardial infarction, or ischemic stroke occurred in 751 of 6930 patients $(10.8 \%)$ in the ticagrelor group and in 740 of 6955 $(10.6 \%)$ in the clopidogrel group (hazard ratio, 1.02; $95 \%$ confidence interval [CI], 0.92 to 1.13 ; 


\begin{tabular}{|c|c|c|}
\hline Characteristic & $\begin{array}{l}\text { Ticagrelor } \\
(\mathrm{N}=6930)\end{array}$ & $\begin{array}{c}\text { Clopidogrel } \\
(\mathrm{N}=6955)\end{array}$ \\
\hline Median age (IQR) - yr & $66(60-72)$ & $66(60-73)$ \\
\hline Female sex — no. (\%) & $1908(27.5)$ & $1980(28.5)$ \\
\hline Median weight (IQR) — kg & $76(66-88)$ & $77(66-88)$ \\
\hline \multicolumn{3}{|l|}{ Inclusion criteria for randomization } \\
\hline Previous revascularization — no. (\%) & $3923(56.6)$ & $3952(56.8)$ \\
\hline$A B I$ value & $0.78 \pm 0.23$ & $0.78 \pm 0.23$ \\
\hline $\mathrm{ABI}$ or $\mathrm{TBI}$ criteria — no. $(\%) \dagger$ & $3007(43.4)$ & $3003(43.2)$ \\
\hline$A B I$ value & $0.63 \pm 0.15$ & $0.63 \pm 0.15$ \\
\hline TBI value & $0.49 \pm 0.14$ & $0.55 \pm 0.27$ \\
\hline \multicolumn{3}{|l|}{ Limb symptoms - no. (\%) } \\
\hline Asymptomatic & 1309 (18.9) & $1292(18.6)$ \\
\hline Mild or moderate claudication & $3674(53.0)$ & $3736(53.7)$ \\
\hline Severe claudication & $1620(23.4)$ & $1608(23.1)$ \\
\hline Pain while at rest & $186(2.7)$ & $192(2.8)$ \\
\hline Minor tissue loss & $107(1.5)$ & $100(1.4)$ \\
\hline Major tissue loss & $33(0.5)$ & $25(0.4)$ \\
\hline Major amputation above the ankle - no. (\%) $\int$ & $161(2.3)$ & $178(2.6)$ \\
\hline \multicolumn{3}{|l|}{ Medical history — no. (\%) } \\
\hline Stroke & $576(8.3)$ & $567(8.2)$ \\
\hline Transient ischemic attack & $279(4.0)$ & $228(3.3)$ \\
\hline Coronary artery disease & $2019(29.1)$ & $2013(28.9)$ \\
\hline Myocardial infarction & $1242(17.9)$ & $1280(18.4)$ \\
\hline \multicolumn{3}{|l|}{ No. of vascular beds affected $\|$} \\
\hline 1 & $3874(55.9)$ & $3930(56.5)$ \\
\hline 2 & $2333(33.7)$ & $2355(33.9)$ \\
\hline 3 & $723(10.4)$ & $670(9.6)$ \\
\hline Diabetes mellitus type I or II & $2639(38.1)$ & $2706(38.9)$ \\
\hline Hypertension & $5437(78.5)$ & $5420(77.9)$ \\
\hline Hyperlipidemia & $5229(75.5)$ & $5251(75.5)$ \\
\hline \multicolumn{3}{|l|}{ Tobacco use - no. (\%) } \\
\hline Never smoked & $1481(21.4)$ & $1503(21.6)$ \\
\hline Current smoker & $2125(30.7)$ & $2164(31.1)$ \\
\hline Former smoker & $3281(47.3)$ & $3249(46.7)$ \\
\hline \multicolumn{3}{|l|}{ Medications before randomization — no. (\%) } \\
\hline Aspirin & $4667(67.3)$ & $4604(66.2)$ \\
\hline Clopidogrel & $2193(31.6)$ & $2280(32.8)$ \\
\hline Statin & $5058(73.0)$ & $5123(73.7)$ \\
\hline Angiotensin-converting-enzyme inhibitor & $2826(40.8)$ & $2809(40.4)$ \\
\hline Angiotensin-receptor blocker & $1741(25.1)$ & $1747(25.1)$ \\
\hline
\end{tabular}

* Plus-minus values are means \pm SD. There were no significant differences between the groups except for transient ischemic attack $(\mathrm{P}=0.02)$. IQR denotes interquartile range.

$\uparrow$ The ankle-brachial index (ABI) and toe-brachial index (TBI) were calculated as the average of measurements obtained at enrollment and at randomization, in which the lowest of the right-side values and left-side values were selected at each visit. Among the patients who were included in the trial on the basis of ABI or TBI criteria, the enrollment of 82 patients (1.2\%) in the ticagrelor group and 93 (1.3\%) in the clopidogrel group was based on TBI criteria.

timb symptoms were categorized with the use of the Rutherford classification. Data were missing for one patient in the ticagrelor group and two in the clopidogrel group. Asymptomatic status refers to the patient's status at the time of randomization, although patients with a history of revascularization may have been asymptomatic at baseline. Minor tissue loss includes ischemic ulceration not exceeding ulcer of the digits of the foot. Major tissue loss includes severe ischemic ulcers or frank gangrene.

$\int$ Major amputation includes above-the-knee and transtibial amputations.

I Coronary artery disease is defined as myocardial infarction, percutaneous coronary intervention, or coronary-artery bypass grafting (CABG).

$\|$ An affected vascular bed was defined by the presence of peripheral artery disease, coronary artery disease, or cerebrovascular disease (including previous stroke, transient ischemic attack, carotid-artery stenosis, or carotid revascularization). 


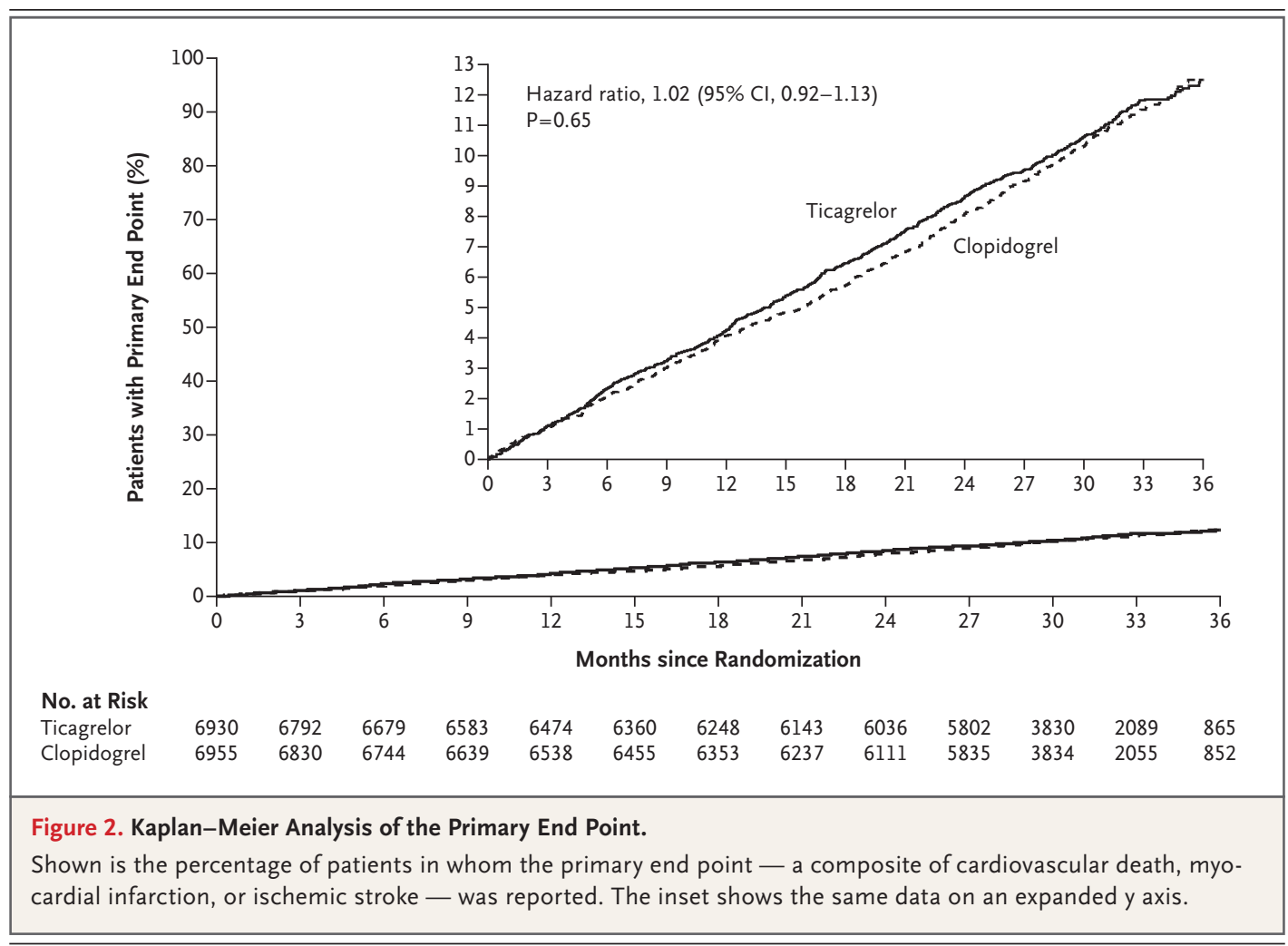

$\mathrm{P}=0.65$ ) (Fig. 2). The only significant betweengroup difference was in the rate of ischemic stroke, which occurred in $1.9 \%$ of the patients in the ticagrelor group, versus $2.4 \%$ in the clopidogrel group (hazard ratio, 0.78 ; $95 \%$ CI, 0.62 to 0.98 ; $\mathrm{P}=0.03$ ) (Table 2).

Other key secondary and composite end points including acute limb ischemia and revascularization were similar in the two groups (Table 2). Overall efficacy findings were consistent among all subgroups, with the exception of patients who had undergone previous coronary or carotid revascularization or previous coronary stenting, in whom an interaction favoring ticagrelor was observed (Fig. S1 in the Supplementary Appendix). Kaplan-Meier curves for the rates of death from cardiovascular causes and all causes are provided in Figures S2 and S3 in the Supplementary Appendix.

\section{SAFETY END POINTS}

The primary safety end point, TIMI major bleeding, occurred in $1.6 \%$ of the patients in both the ticagrelor group and the clopidogrel group (hazard ratio, $1.10 ; 95 \% \mathrm{CI}, 0.84$ to $1.43 ; \mathrm{P}=0.49$ ) (Fig. S4 in the Supplementary Appendix). The rates of fatal bleeding, intracranial bleeding, and TIMI minor bleeding were similar in the two groups (Table 3). There were numerically fewer fatal bleeding events in the ticagrelor group than in the clopidogrel group (10 vs. 20), but there were significantly more bleeding events leading to discontinuation with ticagrelor than with clopidogrel (168 vs. 112; $\mathrm{P}<0.001)$ (Table 3). Ticagrelor was prematurely discontinued more often than clopidogrel during the study (in $30.1 \%$ of patients vs. in $25.9 \%$; hazard ratio, 1.21 ; $95 \% \mathrm{CI}$, 1.14 to 1.29 ; $\mathrm{P}<0.001$ ); discontinuation was driven mainly by the occurrence of dyspnea $(4.8 \%$ in the ticagrelor group vs. $0.8 \%$ in the clopidogrel group) and any bleeding event that was documented by the investigator on a case-report form $(2.4 \%$ vs. $1.6 \%, \mathrm{P}<0.001$ for both comparisons). Overall, the TIMI major bleeding events were few and generally consistent among subgroups (Fig. S5 in the Supplementary Appendix). Additional information about adverse events is provided in Tables S1 through S3 in the Supplementary Appendix.

\section{DISCUSSION}

In our study involving patients with peripheral artery disease, we found that monotherapy with ticagrelor was not superior to clopidogrel in re- 


\begin{tabular}{|c|c|c|c|c|c|c|}
\hline \multirow[t]{2}{*}{ Outcome } & \multicolumn{2}{|c|}{$\begin{array}{l}\text { Ticagrelor } \\
(\mathrm{N}=6930)\end{array}$} & \multicolumn{2}{|c|}{$\begin{array}{l}\text { Clopidogrel } \\
(\mathrm{N}=6955)\end{array}$} & \multirow[t]{2}{*}{$\begin{array}{l}\text { Hazard Ratio } \\
(95 \% \mathrm{CI})\end{array}$} & \multirow[t]{2}{*}{ P Value } \\
\hline & no. (\%) & $\begin{array}{l}\text { event rate per } \\
100 \text { patient- } y r\end{array}$ & no. (\%) & $\begin{array}{l}\text { event rate per } \\
100 \text { patient- } y r\end{array}$ & & \\
\hline $\begin{array}{l}\text { Primary outcome: cardiovascular death, } \\
\text { myocardial infarction, or ischemic } \\
\text { stroke }\end{array}$ & $751(10.8)$ & 4.47 & $740(10.6)$ & 4.36 & $1.02(0.92-1.13)$ & 0.65 \\
\hline Cardiovascular death & $363(5.2)$ & 2.08 & $343(4.9)$ & 1.95 & $1.07(0.92-1.23)$ & 0.40 \\
\hline Myocardial infarction & $349(5.0)$ & 2.40 & $334(4.8)$ & 2.38 & $1.06(0.91-1.23)$ & 0.48 \\
\hline Ischemic stroke & $131(1.9)$ & 0.84 & $169(2.4)$ & 1.00 & $0.78(0.62-0.98)$ & 0.03 \\
\hline $\begin{array}{l}\text { Key secondary efficacy outcome: cardio- } \\
\text { vascular death, myocardial infarc- } \\
\text { tion, ischemic stroke, or acute limb } \\
\text { ischemia requiring hospitalization }\end{array}$ & $839(12.1)$ & & $833(12.0)$ & & $1.02(0.92-1.12)$ & 0.74 \\
\hline \multicolumn{7}{|l|}{ Other secondary outcomes } \\
\hline Death from any cause & $628(9.1)$ & & $635(9.1)$ & & $0.99(0.89-1.11)$ & 0.91 \\
\hline $\begin{array}{l}\text { Cardiovascular death, myocardial infarc- } \\
\text { tion, or ischemic or hemorrhagic } \\
\text { stroke }\end{array}$ & $766(11.1)$ & & $759(10.9)$ & & $1.02(0.92-1.13)$ & 0.72 \\
\hline Hospitalization for acute limb ischemia & $117(1.7)$ & 0.86 & $115(1.7)$ & 0.79 & $1.03(0.79-1.33)$ & 0.85 \\
\hline Lower-limb revascularization & $846(12.2)$ & & $892(12.8)$ & & $0.95(0.87-1.05)$ & 0.30 \\
\hline $\begin{array}{l}\text { Coronary or peripheral revasculariza- } \\
\text { tion, including limb, mesenteric, } \\
\text { renal, carotid, or other type }\end{array}$ & 1211 (17.5) & & $1250(18.0)$ & & $0.97(0.90-1.05)$ & 0.46 \\
\hline
\end{tabular}

* Event rates are provided only for the adjudicated events that include either the primary efficacy outcome and its components or acute limb ischemia. $\mathrm{Cl}$ denotes confidence interval.

ducing the rate of cardiovascular events; the rate of major bleeding was similar in the two groups. There was also no significant between-group difference in a key secondary end point of acute limb ischemia. Patients receiving ticagrelor discontinued treatment more often than did those receiving clopidogrel, mainly because of dyspnea and minor bleeding, which are well-described adverse effects of the drug.

These overall findings should be placed in the context of what was known before we conducted the EUCLID trial. Antiplatelet therapy is considered to be a critical component of the management of cardiovascular risk in patients with peripheral artery disease. However, this recommendation is based on limited data regarding two antiplatelet agents - aspirin and clopidogrel. Specifically, patients receiving aspirin had a modest $12 \%$ lower risk of cardiovascular events than those receiving placebo in a meta-analysis involving approximately 5000 patients. ${ }^{10}$ In two large clinical trials, patients with asymptomatic atherosclerosis (which was defined as an abnormal ABI value) were randomly assigned to receive aspirin or pla- cebo. ${ }^{11,12}$ In those trials, aspirin was not superior to placebo in preventing cardiovascular events. In the randomized Clopidogrel versus Aspirin in Patients at Risk of Ischemic Events (CAPRIE) trial, ${ }^{3}$ investigators compared clopidogrel with aspirin monotherapy in a broadly defined stable population of patients with atherosclerotic disease, including coronary artery disease, peripheral artery disease, and cerebrovascular disease. The overall trial showed a significant benefit for clopidogrel over aspirin that was driven mainly by the subgroup of patients with peripheral artery disease, in whom there was a $23.8 \%$ risk reduction. These results from CAPRIE established clopidogrel as the first therapy for peripheral artery disease to be approved by the Food and Drug Administration. In the Clopidogrel for High Atherothrombotic Risk and Ischemic Stabilization, Management, and Avoidance (CHARISMA) trial, investigators who compared aspirin plus clopidogrel with aspirin monotherapy in a broad, high-risk population of patients with atherosclerosis found no significant benefit for clopidogrel in the risk of cardiovascular events in the overall population; however, there 


\begin{tabular}{|c|c|c|c|c|}
\hline \multirow[t]{2}{*}{ Outcome } & $\begin{array}{l}\text { Ticagrelor } \\
(\mathrm{N}=6910)\end{array}$ & $\begin{array}{l}\text { Clopidogrel } \\
(\mathrm{N}=6932)\end{array}$ & $\begin{array}{c}\text { Hazard Ratio } \\
\text { (95\% CI) }\end{array}$ & P Value \\
\hline & \multicolumn{2}{|c|}{ no. (\%) } & & \\
\hline Primary safety outcome: TIMI major bleeding & $113(1.6)$ & $109(1.6)$ & $1.10(0.84-1.43)$ & 0.49 \\
\hline Intracranial bleeding & $34(0.5)$ & $34(0.5)$ & $1.06(0.66-1.70)$ & 0.82 \\
\hline Fatal bleeding & $10(0.1)$ & $20(0.3)$ & $0.53(0.25-1.13)$ & 0.10 \\
\hline TIMI minor bleeding & $84(1.2)$ & $67(1.0)$ & $1.32(0.96-1.83)$ & 0.09 \\
\hline Adverse events leading to discontinuation ${ }^{\top}$ & $1063(15.4)$ & $766(11.1)$ & & \\
\hline Dyspnea & $330(4.8)$ & $52(0.8)$ & & $<0.001$ \\
\hline Any bleeding & $168(2.4)$ & $112(1.6)$ & & $<0.001$ \\
\hline
\end{tabular}

* TIMI denotes Thrombolysis in Myocardial Infarction.

$\uparrow$ A total of $30.1 \%$ of patients in the ticagrelor group and $25.9 \%$ in the clopidogrel group prematurely discontinued the assigned study drug during follow-up. Included in this group were patients who discontinued the study drug because of adverse events, those in whom the primary end point occurred, and those who died.

$¥$ This category includes adverse events leading to the permanent discontinuation of a study drug because of a bleeding event that was documented by the investigator on a case-report form; these events included unadjudicated minimal bleeding.

was a nonsignificant trend in the subgroup of patients with peripheral artery disease..$^{13}$ Dual antiplatelet therapy was associated with an increased risk of bleeding. ${ }^{13}$ On the basis of this evidence, clopidogrel monotherapy has been the preferred therapy to manage the atherothrombotic risk in patients with peripheral artery disease.

In the Study of Platelet Inhibition and Patient Outcomes (PLATO), in which investigators compared ticagrelor with clopidogrel in patients receiving aspirin (dual antiplatelet therapy), they found that ticagrelor was superior in reducing the rate of cardiovascular events in patients with acute coronary syndromes. ${ }^{5}$ In the Prior Heart Attack Using Ticagrelor Compared to Placebo on a Background of Aspirin-Thrombolysis in Myocardial Infarction 54 (PEGASUS-TIMI 54) study involving patients with previous myocardial infarction, ticagrelor was more effective than placebo among patients receiving aspirin (dual antiplatelet therapy vs. aspirin monotherapy) in reducing the rate of cardiovascular events. ${ }^{6}$ In both the PLATO and PEGASUS trials, the presence of concomitant peripheral artery disease was associated with an increased risk of ischemic events and with a consistent benefit for ticagrelor in comparisons with the overall trial populations. ${ }^{7,8}$ Given the evidence, ticagrelor was considered to be a potent agent with potential benefit in patients with peripheral artery disease.

In light of the previous study results, how can we interpret the findings of similar treatment ef- fects for ticagrelor and clopidogrel in the EUCLID trial? A major consideration is that clopidogrel represents an effective active comparator. In our trial, we excluded patients who were homozygous for loss-of-function alleles to clopidogrel before randomization. Furthermore, the results of the CAPRIE trial suggest that clopidogrel may be particularly effective in patients with peripheral artery disease. In addition, the patients in our trial were enrolled on the basis of having peripheral artery disease, with a minority having concomitant clinical coronary artery disease. These patients may have important phenotypic and biologic differences from those with predominantly acute and chronic coronary artery disease. ${ }^{14} \mathrm{Fi}$ nally, patients with peripheral artery disease may have competing risks and drivers of clinical events.

These findings should inform the field of vascular medicine. Given the similar rates of cardiovascular and bleeding events in our two trial groups, ticagrelor and clopidogrel appear to be similar in patients with peripheral artery disease, although the occurrence of side effects prompted more discontinuations of ticagrelor than of clopidogrel. In addition, our findings show the hazards of extrapolating evidence from patients with coronary artery disease to those with peripheral artery disease. In our trial, the observed cardiovascular event rates in the two groups $(4.42 \%$ per 100 patient-years) combined with the rates of acute limb ischemia (0.83\% per 100 patient-years) show the 
need for continued clinical improvement. Therefore, future trials should evaluate well-defined populations of patients with peripheral artery disease, including those with stable disease and those who have undergone revascularization. Finally, the risks and harms of combinations of antithrombotic therapies need to be evaluated prospectively, particularly when such drugs are used in patients who have undergone revascularization, in whom drugs and devices are used together to treat symptomatic disease.

Some limitations of our trial should be noted. Aspirin was not included in the trial because of constraints involved in the feasibility of conducting a three-group study and complications in blinding when dual antiplatelet therapy would be clinically needed after randomization. Therefore, we cannot draw direct conclusions about the effect of the studied agents as compared with aspirin among patients with peripheral artery disease who were enrolled in our study. However, as previously noted, clopidogrel was the agent of choice, given the available evidence showing its nominal superiority over aspirin in a broad population of patients with atherosclerosis, especially since the effect was driven by the result in patients with peripheral artery disease. $^{3}$

In conclusion, in patients with symptomatic peripheral artery disease, ticagrelor was not superior to clopidogrel for the reduction of cardio- vascular events, and each drug was associated with similar rates of major bleeding. However, ticagrelor was discontinued more frequently than clopidogrel because of the occurrence of side effects (mainly dyspnea and minor bleeding).

Supported by AstraZeneca.

Dr. Fowkes reports receiving consulting fees from Bayer and Merck; Dr. Berger, receiving fees for serving on advisory boards from Janssen, Merck, and Takeda; Dr. Baumgartner, receiving fees for serving on a steering committee from AstraZeneca, fees for serving on advisory boards from Bayer and Sanofi, and grant support from Abbott Vascular, Cook Medical, Optimed, Terumo Medical, Promedics, Amgen, and Boston Scientific; Drs. Held, Katona, and Blomster and Mr. Millegård, being employees of AstraZeneca, and Dr. Held, having an equity interest in AstraZeneca; Dr. Mahaffey, receiving consulting fees from BAROnova, Bayer, Bio2 Medical, Boehringer Ingelheim, Bristol-Myers Squibb, Cubist, Eli Lilly, Epson, Forest Laboratories, GlaxoSmithKline, Johnson \& Johnson, Medtronic, Merck, MyoKardia, Omthera Pharmaceuticals, Portola Pharmaceuticals, Purdue Pharma, the Medicines Company, Theravance, Vindico, and WebMD, grant support to his institution from Amgen, Daiichi Sankyo, Johnson \& Johnson, Medtronic, Merck, St. Jude Medical, and TenaxTherapeutics, and having an equity interest in BioPrint Fitness; Dr. Norgren, receiving fees for serving on steering committees from Bayer, AnGes MG, and Pluristem Therapeutics, receiving fees for serving on an advisory board from Cesca Therapeutics, receiving consulting fees from Mitsubishi Tanabe Pharma, and receiving grant support from AnGes MG and Mitsubishi Tanabe Pharma; and Dr. Patel, receiving consulting fees from Bayer, Cardiovascular Systems, Genzyme, Janssen Research and Development, Medtronic, and Merck and receiving grant support to his institution from Cardiovascular Systems, HeartFlow, Janssen Research and Development, Johnson \& Johnson, Maquet, and Medtronic. No other potential conflict of interest relevant to this article was reported.

Disclosure forms provided by the authors are available with the full text of this article at NEJM.org.

We thank the patients who participated in this trial; and Elizabeth Cook of the Duke Clinical Research Institute for providing editorial assistance.

\section{REFERENCES}

1. Bhatt DL, Steg PG, Ohman EM, et al. International prevalence, recognition, and treatment of cardiovascular risk factors in outpatients with atherothrombosis. JAMA 2006;295:180-9.

2. Steg PG, Bhatt DL, Wilson PW, et al. One-year cardiovascular event rates in outpatients with atherothrombosis. JAMA 2007;297:1197-206.

3. CAPRIE Steering Committee. A randomised, blinded, trial of clopidogrel versus aspirin in patients at risk of ischaemic events (CAPRIE). Lancet 1996;348:1329-39. 4. Morrow DA, Braunwald E, Bonaca MP, et al. Vorapaxar in the secondary prevention of atherothrombotic events. N Engl J Med 2012;366:1404-13.

5. Wallentin L, Becker RC, Budaj A, et al. Ticagrelor versus clopidogrel in patients with acute coronary syndromes. N Engl J Med 2009;361:1045-57.

6. Bonaca MP, Braunwald E, Sabatine MS. Long-term use of ticagrelor in patients with prior myocardial infarction. N Engl J Med 2015;373:1791-800.
7. Patel MR, Becker RC, Wojdyla DM, et al. Cardiovascular events in acute coronary syndrome patients with peripheral arterial disease treated with ticagrelor compared with clopidogrel: data from the PLATO Trial. Eur J Prev Cardiol 2015;22 734-42.

8. Bonaca MP, Bhatt DL, Storey RF, et al Ticagrelor for prevention of ischemic events after myocardial infarction in patients with peripheral artery disease. J Am Coll Cardiol 2016;67:2719-28.

9. Berger JS, Katona BG, Jones WS, et al. Design and rationale for the Effects of Ticagrelor and Clopidogrel in Patients with Peripheral Artery Disease (EUCLID) trial. Am Heart J 2016;175:86-93.

10. Berger JS, Krantz MJ, Kittelson JM, Hiatt WR. Aspirin for the prevention of cardiovascular events in patients with peripheral artery disease: a meta-analysis of randomized trials. JAMA 2009;301:190919.

11. Fowkes FG, Price JF, Stewart MC, et al. Aspirin for prevention of cardiovascular events in a general population screened for a low ankle brachial index: a randomized controlled trial. JAMA 2010;303: 841-8.

12. Belch J, MacCuish A, Campbell I, et al. The Prevention of Progression of Arterial Disease and Diabetes (POPADAD) trial: factorial randomised placebo controlled trial of aspirin and antioxidants in patients with diabetes and asymptomatic peripheral arterial disease. BMJ 2008;337: a1840.

13. Bhatt DL, Fox KAA, Hacke W, et al. Clopidogrel and aspirin versus aspirin alone for the prevention of atherothrombotic events. N Engl J Med 2006;354:170617.

14. Nambi V, Kimball KT, Bray PF, et al. Differences in responses of platelets to fluid shear stress in patients with peripheral artery disease (PAD) and coronary artery disease (CAD). Platelets 2009;20: 199-205.

Copyright (c) 2016 Massachusetts Medical Society. 